\title{
Using Shaanxi cultural resources to promote the local animation brand identity
}

\author{
Kang Kai \\ Art College of Xi'an University, 710065
}

Keywords: Shaanxi Cultural Resources; Folk Art; Cartoon Brand; Identification

Abstract: On the one hand, the purpose of this paper is to study how to make full use of the cultural resources with Shaanxi characteristics, give full play to the advantages of local characteristics, achieve the effect of establishing the brand of animation in Shaanxi, and further improve their own recognition. Make Shaanxi animation industry enter the virtuous circle of sustainable development. On the other hand, it explores how to promote the inheritance and development of Shaanxi local characteristic traditional culture through effective and reasonable utilization and development. By analyzing the classification and characteristics of Shaanxi characteristic culture resources, this paper sums up the innovative points and schemes which can be used in the development and establishment of animation brand,and explores the development direction of Shaanxi animation brand and the inheritance of characteristic traditional culture.

It has been a consensus of local cultural departments and animation enterprises to use local cultural resources to import powerful new blood for animation industry and promote the establishment and development of animation brand. However, Shaanxi is still at the embryonic stage of budding exploration in the establishment and identification of animation brands. Therefore, the author attempts to build a win-win development plan for both through the investigation of existing animation projects and sorting out the local cultural resources with local characteristics in Shaanxi

1. An analysis of the current situation of Shaanxi animation brands in the use of local traditional cultural resources

It is in line with the National "13th five-year Plan" to develop the original animation project with local characteristic cultural resources, and it is also in line with the core spirit of the 19thNationallCongresss to make the local animation industry on the road of sustainable development .However, Shaanxi's efforts in this regard are obviously not enough. There is a clear gap in quality as well as quantity. Originality and high quality are also urgent problems to be solved, and ways and means need to be urgently adjusted For the development of the local characteristics of the animation industry to make changes $\backslash$

Only works with characteristics can go out, such as in the subject matter, modeling characteristics, historical and cultural heritage should be considered. Currently, Shaanxi animation works such as Xi'an Changfeng Film and Animation Company's original animation series "Qin 
Qinbao", "Shaanxi Quyi", "Red Yan 'an", "Yulin Winter Festival" , the animation image "the five treasures of Qin Mountains" produced by Shaanxi Jiahe Film and TV Animation Company is a relatively mature work, which is worth learning and learning. "Qin Qinqinbaobei", created by Changfeng Animation Company, is especially worth mentioning. The main character is modeled on the image of the terracotta warriors in the Terracotta Army. The theme of the short film series focuses on the diverse experiences of Qin Qinbei to illustrate his views on contemporary issues of global concern, such as urban development, environmental protection, war and Peace It expresses the concern of protecting the environment, loving peace, harmonious society and other modern values, and its use of humorous performance, fashionable and classic pictures, high-quality and high-level production technology has touched the hearts of the audience. Qin Qinbeibei has also launched a series of documentaries, "Qin Qinbeibei travels in China", which uses the technology of combining three-dimensional animation with live shooting to give a very comprehensive introduction to local customs, special snacks, history and culture It has also developed brand franchises in Terracotta Army and a range of spin off products for the tourism industry. However, due to insufficient publicity, in the follow-up works failed to follow-up, resulting in the establishment of the brand has not yet achieved the desired results, there is still room for further development and improvement.

In addition, there are few animation works that use traditional local cultural elements in Shaanxi, and there is a lack of animation brand creation. The traditional culture of Shaanxi characteristics of the resources available, the failure to make reasonable use of it is a pity.

2. Sorting out the resources of Shaanxi traditional culture and the induction taking follk art resources as an example

\section{1 sorting out the resources of Shaanxi Traditional Culture}

Shaanxi is one of the main birthplaces of Chinese culture, and its historical and cultural heritage is very deep, so it plays an important role in Chinese traditional cultural resources.

There is no doubt that letting the local traditional characteristic cultural element infuse the animation work can cause it to have the formidable vitality. The author has carried on the preliminary classification combing to this, and the main categories are applied arts, legends, historical relics, history and culture, historical figures, Quyi, folk songs, dialects, folk arts, food and beverage, traditional forms of entertainment and so on. The cultural elements included in these categories, such as shadow play in the old tune, clay sculpture in Fengxiang County, terra cotta warriors, Qin embroidery, Qin Opera, Huangtu painting school, history and culture of the Qin, Han and Tang dynasties, historical sites, Shaanxi dialects, Shanbei paper-cut, Shanbei folk songs, special food, Folk Tales, Academy culture and other historical, cultural and artistic materials with local characteristics are very available and can be tapped. In this paper, the author further take folk art resources as an example to find out cultural resources which can be used in the creation of cartoon brand, and can be extended to other types of resources.

\subsection{A summary of folk art resources as an example}

Shaanxi is one of the important birthplaces of Chinese civilization, so its historical and cultural heritage is extremely rich. In history, the capital of 13 dynasties was built in Shaanxi, leaving rich folk cultural heritage. There are many kinds of folk art resources in Shaanxi, which are divided into the following categories from the visual form: 


\subsubsection{Visual plane classes}

According to the plane visual induction mainly Folk paper-cut, shadow art, Qin embroidery, quyi mask, woodblock New Year, murals, water and land painting, peasant painting and other forms. The art form has its own characteristics, both Shaanxi local shape and color characteristics of the common, exaggerated deformation, simple, naive, and unique due to the different technology and geographical

\subsubsection{Solid Modeling Classes}

According to the three-dimensional modeling, there are mainly blue brick relief, stone carving, surface plastic, heap plastic, modeling, clay sculpture, large wax and other forms. Its artistic characteristics are abstract and general, simple and concise, but the different uses of materials selection and production methods have also created their different aesthetic characteristics.

\section{Exploration on innovation of Folk Art Resources in Shaanxi Province}

\subsection{Extraction of aesthetic characteristics and artistic expression form of Folk Art Resources}

We should analyze the aesthetic characteristics of each cultural art form and extract its artistic expression effectively. Take the clay sculpture in Fengxiang County as an example:

The clay sculpture in Fengxiang County is also known as the painted clay sculpture. Is a pure hand-made folk art,plate soil as raw material, through and mud, wake mud, modeling, molding, rolling, billet, wash mill, laying, outline, painting, glazing and more than a dozen processes completed.

We should analyze the aesthetic characteristics of each cultural art form and extract its artistic expression effectively. Take the clay sculpture in Fengxiang County as an example:

The clay sculpture in Fengxiang County is also known as the painted clay sculpture It is a kind of folk art made by hand. It is made of board clay as raw material. It has been finished by dozens of processes, such as mixing clay, Waking Clay, modeling, Molding, rolling, rolling, washing, laying lining, lining, painting and painting.

\subsubsection{Styling Features}

The clay sculptures in Fengxiang County can be classified into three categories: seated figure, hanging piece, standing figure, groceries and juggling. The main animals, characters for the theme to shape integrity, fullness and fullness for the United States. The use of addition sculpture approach, the use of a variety of geometric formation of the image of the stack, and then refined from the repair of sculpture .Therefore formed the geometric summary and exaggerated deformation of the shape characteristics.

\subsubsection{Ornamentation Characteristics}

Fengxiang County Clay Sculpture is decorated with flowers, birds, fish, insects or plant motifs, most commonly in the form of auspicious symbols and allegories.

The main line, dividing line, following line and winding line are used to outline the shape structure of the main body, and the lines are steady and powerful Decorative Anomaly. Through these points line density thick, rigid and soft straight changes make clay unique decorative and innovative aesthetic feeling, line diversity and unity, harmony and integrity, in line with the aesthetic interest of contemporary groups. Therefore, Fengxiang County clay sculpture has the 
aesthetic characteristics of strong decoration, deep implication and abstraction in the aspect of pattern elements. It not only inherits the aesthetic spirit of traditional folk art, but also is loved by Contemporary Consumers

\subsubsection{Color Features}

Clay figurines in Fengxiang County are decorated with bold and uninhibited ink lines and decorated with the five elements. The works are mainly of two types: Colored Drawing and Plain Drawing.

The first is painted clay sculpture. Its use of colour is influenced by $\mathrm{Wu}$ Xing to the traditional "five-color" green, red, black, white, yellow five-color drawing. High Chroma, bright and full, weaken the environmental color relation, show the color relation with the flat method of drawing color, strengthen the contrast relation of the color, and make the color present the simple and atmospheric layering.

The second is clay sculpture. Plain painting, also known as ink line painting, is the pouring of good white clay tires with ink outline of the outline, and then use a wide range of lines outline figures, animals and the subtle details of decorative patterns. The main line, dividing line, following line and winding line are used to depict the beauty and purity of Fengxiang County's clay sculpture. The depictions in Fengxiang County's clay sculptures are terse and terse, incorporating human elements into the compositions. The beauty of the works is highly congenial to the rustic folk.

Based on the above analysis and extraction of the various characteristics of Fengxiang County Clay Sculpture, in the animation works of its essence, retain its typical elements, its reasonable integration in the animation role, the design of the scene It not only inherits the visage of Fengxiang County's clay sculpture, but also gives the works new vitality.

\subsection{Organic fusion of featured material and contemporary values}

After extracting the usable elements from the cultural resources, we can not copy them directly, but combine them with the stories with modern values. Can Be in the traditional historical and cultural materials or legends for material, but the story should be adapted to contemporary audience's psychological needs and aesthetic needs. For example, the animated film Monkey King: Hero Is Back adapted the traditional content of journey to the West, based on its basic paradigm and logic It explains the modern proposition of seeking beginner's mind and self-salvation. This kind of excavation and development makes the traditional artistic image richer and fuller, obtains the more profound thought and the connotation, and also makes the re-created and re-interpreted works acquire a kind of modernity which is quite different from the traditional To reap the spiritual and emotional resonance of modern people

Therefore, it is far from enough to only rely on local traditional stories as the subject matter and use the local characteristic modelling element. For local cultural resources, putting on the coat of fashion, injecting fresh blood and becoming a modern animation is the real rational use rather than simple appropriation of its shape, story, etc. .

\section{Analysis of expected results and advantages}

Taking the clay sculpture of Fengxiang County as an example,the author analyzes its typical aesthetic features and proposes to take its essence in the creation of animation works, retain its typical elements, and integrate it reasonably into the design of animation characters and scenes It not only inherits the visage of Fengxiang County's clay sculpture, but also gives the works new vitality. Through the advantages of the dissemination of cartoon works, this folk art form of clay 
sculpture in Fengxiang County can be brought to more audiences, on the basis of which a series of innovative products can be developed, forming a series of cultural and creative products and derivative products And screen image, forming a complete product image, and then set up a landmark brand animation, but also for the inheritance and development of Fengxiang County clay sculpture has brought new breakthroughs.

The use of local cultural resources can make Shaanxi animation industry on the road of sustainable development and no longer copy,so that the title is available, there are materials available more creative and vitality, and can improve their brand recognition. No longer just copy Hollywood, Disney or Japanese and Korean animation, or will only outsourcing not original, so Shaanxi animation enterprises in the development of local characteristics of the project competition triggered more outstanding works We will further enhance the competitiveness and originality of all enterprises. So that the real high-level high-quality original works can be highlighted.

Secondly, through cross-border cooperation with other industries, the animation industry to tourism, derivative surrounding, cultural and creative expansion of the industrial chain loop. The use of local cultural resources, low cost, high efficiency, on the latter derivatives industry chain is very helpful to promote Shaanxi's culture, tourism and other industries have a strong role in promoting. To further build a complete local characteristics of animation brand industry chain, set up a strong brand image and improve brand recognition, so that Shaanxi animation industry use a new image as a pillar industry. Through the effective combination of the two advantages, it can promote the inheritance and development of Shaanxi traditional culture with local characteristics, and achieve the win-win effect of establishing cartoon brand, thus inheriting the traditional culture.

\section{References}

[1] Liu Wenhua. Research on folk art elements in animation character modeling [D]. Xi'an Polytechnic University, 2017.

[2] Liu Yan. Study on the color of Chinese Folk Art [D] Shandong University, 2016.

[3] Kang Kai On the factors leading Chinese original animation to a new peak in Monkey King:[J] Peony,2015,(8x) 21-22

[4] Dai Zhen.Research on the application of Chinese folk art elements in animation character design [D] Northeast Normal University, 2016.

[5] Wang Zheng. The application of folk art in modern animation modeling design [J] Popular Culture, 2011(16) 96-97

[6] Wang Gang,red. Shaanxi folk art modelling in animation modelling design creation practice [J] Western leather, 2018, 40(12) 150-151. 